UNDERGRADUATE RESEARCH IN NATURAL AND CLINICAL SCIENCE AND TECHNOLOGY (URNCST) JOURNAL Read more URNCST Journal articles and submit your own today at: https://www.urncst.com

CONFERENCE ABSTRACT BOOK

OPEN ACCESS

\title{
The University of Toronto Scarborough Psychology and Neuroscience Departmental Association (PNDA) 2021 Academic Research Panel
}

\author{
Ilakkiah Chandran, HBSc Candidate [1]*, Mahnoor Khan, HBSc Candidate [1], Zanib Sarwar, \\ HBSc Candidate [1] \\ [1] Department of Psychology, University of Toronto Scarborough, Toronto, Ontario, Canada \\ M1C 1A4
}

*Corresponding Author: ilakkiah.chandran@mail.utoronto.ca

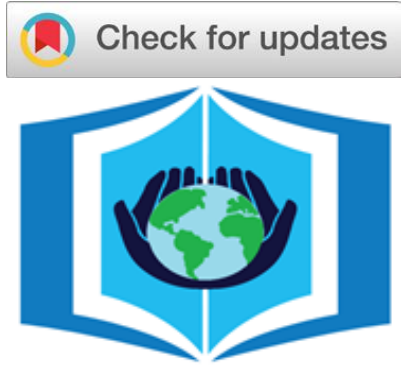

URNCST Journal

"Research in Earnest"

\begin{abstract}
The Psychology and Neuroscience Departmental Association (PNDA) advocates on behalf of its members to the Department of Psychology at University of Toronto Scarborough and fosters academic excellence and career growth. PNDA provides academic and professional support by creating opportunities to interact and network with like-minded individuals while serving as a hub for all matters pertaining to the Psychology, Mental Health studies, and Neuroscience programs, thereby connecting members, students, faculty, staff, organizations, institutions, companies, and communities. The Academic Research Panel (ARP) is a two-day event focused on fostering research and student engagement amongst UTSC students specifically in the psychology, neuroscience and mental health studies programs. The ARP was launched this year by PNDA executives to provide a platform for students to network with like-minded individuals and showcase their scientific work. The first day consisted of a professor and alumni panel and the secondary day highlighted research from undergraduate student presenters.
\end{abstract}

Keywords: neuroscience, psychology, mental health studies

Table of Contents

Undergraduate Research Presentations pg. A2-A5

\section{Conference Abstracts}

Note: These abstracts have been reproduced directly from the material supplied by the authors, without editorial alteration by the staff of the URNCST Journal. Insufficiencies of preparation, grammar, spelling, style, syntax, and usage are the authors. 
UNDERGRADUATE RESEARCH IN NATURAL AND CLINICAL SCIENCE AND TECHNOLOGY (URNCST) JOURNAL

Read more URNCST Journal articles and submit your own today at: https://www.urncst.com

Undergraduate Research Presentations

Addressing racial inequities in mental health care

Anuijan Chandran, HBSc Candidate [1]

[1] Department of Psychology, University of Toronto Scarborough, Toronto, Ontario, Canada M1C 1A4

Over the last year, the global community has been burdened with the consequences of the COVID-19 pandemic. Many individuals have faced challenges maintaining their well-being, overcoming challenges related to food insecurity and financial obstacles. However, aside from the battle against the public health crisis, we as a global community have also seen increased reports of race-based violence and crime including anti-black racism and xenophobia. In mental healthcare settings, there are evident disparities in accessibility, service delivery and overall experiences of racial minorities in comparison to Caucasian users. For example, the American Psychiatry Association report that although racial minorities are more likely to experience increased mental health challenges, only $31 \%$ of Black and Hispanics and $22 \%$ of Asians receive mental health services compared to $48 \%$ of Caucasians. This disparity is also more significant amongst women of racial minorities. The evident discrepancy in mental health experiences amongst racial minorities calls for immediate action to ensure equity throughout the population. To combat these racial disparities, I propose tackling this concern using a holistic approach focusing on healthcare professional training, accessibility and awareness mental health services amongst individuals. Firstly, utilizing a holistic model when training mental healthcare professional training can help increase cross-cultural awareness. A holistic model of training will train professionals to account for differences in experiences, diagnoses, and symptoms of racial minorities to warrant appropriate service delivery. Secondly, increasing mental health service accessibility to racial minorities can assist in removing barriers associated with acquiring the necessary care. Lastly, increasing the mental health awareness through educational workshops, public health campaigns will reduce the stigma within the community and increase use of the services. In conclusion, racial minorities face disparities related to the accessibility of mental health care. In order to mitigate these concerns, healthcare professional training, accessibility and awareness must be targeted.

Stigma towards individuals with schizophrenia: Examining the effects of negative symptoms and diagnosis awareness on preference for social distance Aqsa Zahid, HBSc Candidate [1], Michael W. Best, PhD [1,2]

[1] Department of Psychology, University of Toronto Scarborough, Toronto, Ontario, Canada M1C 1A4

[2] Graduate department of Psychological Clinical Science, University of Toronto Scarborough, Toronto, Ontario, Canada M1C $1 A 4$

Social exclusion towards individuals with schizophrenia can occur as a result of stigmatizing attitudes towards the diagnosis or as a response to observing atypical behaviours resulting from symptoms. The present study examined social exclusion towards schizophrenia as a function of diagnosis awareness and presence of negative symptoms. 64 healthy participants watched four different videos of confederates who were either labelled / not labelled with schizophrenia and displayed / did not display negative symptoms. Participants ranked their preference for social interaction with individuals in ten different activities and were told that they would complete the activities based on their rankings. A significant interaction between label and symptoms was found as knowledge of diagnosis increased desire for social distance if symptoms were absent and decreased desire for social distance if symptoms were present. A main effect of symptom presence was also found as participants displayed greater desire to complete activities with individuals not displaying symptoms than participants displaying symptoms but there was no effect of diagnostic label. Social exclusion appears to be dependent on both presence of negative symptoms and knowledge of diagnosis. It may be useful to focus on increasing public acceptance of specific symptom presentations in public mental health campaigns. (https://doi.org/10.1016/j.psychres.2021.113724).

\section{Imagination, culture and COVID-19}

Claire Caluag, HBSc Candidate [1]

[1] Department of Psychology, University of Toronto Scarborough, Toronto, Ontario, Canada M1C 1A4

This research study aims to understand the lived experiences of anime fans who watch different genres of anime and why they may continue to watch or re-watch several seasons of the same show. In response to the phenomena, "What sets anime apart from the other creative outlets accessible to you?" I examined to what extent individuals are invested in anime and the extent to which interest evolves into the desire to belong to a community and become a devoted anime fan. Part of this research involves eight episodes of qualitative interviews, which consists of a conversational format and a specific criteria 
UNDERGRADUATE RESEARCH IN NATURAL AND CLINICAL SCIENCE AND TECHNOLOGY (URNCST) JOURNAL Read more URNCST Journal articles and submit your own today at: https://www.urncst.com

devoted fan who watched a minimum of 350 episodes of anime. Each participant shares two episodes of their lives when they watched an anime and shares their experience watching it and what they remember in doing so (and a follow-up interview after two episodes). Thus, the focus is to understand each individual's lifestyle and what satisfaction anime contributes to the individual that other activities cannot.

Types of anger and sharing on Facebook: A research study Gabriella Patro, BSc Candidate [1], Kosha D. Bramesfeld, PhD [1] [1] Department of Psychology, University of Toronto Scarborough, Scarborough, Ontario, Canada MIC 1A4

Social media activism has become more popular in the last few years due to its ability to quickly disseminate information regarding injustices. This research will look at what types of anger are more effective at inducing collective action in relation to the Black Lives Matter (BLM) movement. Which leads to a higher number of sharing on Facebook: posts that invoke moral outrage or anger-focused posts? Anger-focused posts include self-focused anger and outgroup anger which both blame the advantaged group (i.e. White people) for inequalities that the disadvantaged group experiences. Moral outrage directs blame at a third party, (e.g. a government) for these inequalities. Previous research has focused greatly on moral outrage and self-focused anger, but not outgroup anger. While moral outrage has theoretically and empirically been shown to lead to collective action, it is unknown whether it is a more effective predictor of collective action than self-focused anger and outgroup anger. 234 publicly available Facebook posts with at least 1000 followers/likes were used regarding BLM: 101 from White allyship accounts and 133 from Black activism accounts. I predict that moral outrage posts will have a higher number of shares on Facebook than anger-focused posts, but this will vary by group identity (i.e. White vs Black). Future research should spend more time collecting and analyzing the posts with trained raters, given this study's time constraints and poor interrater reliability. I would like to acknowledge my classmates and the course instructor for PSYC71 in assistance of this project, as the data collection was a joint class effort.

Parents' song rendition at home: Individual variability in pitch and tempo Hanqi Chen, HBSc Candidate [1], Laura Cirelli, PhD [1], Haley Kragness, PhD [1] [1] Department of Psychology, University of Toronto Scarborough, Toronto, Ontario, Canada M1C 1A4

Singing is a common component in parents' day-to-day interactions with infants, which can convey both social and emotional meaning to infants. Previous research has documented remarkable pitch and tempo consistency in mothers' renditions of frequently sung songs, measured in the lab one week apart. Interestingly, however, infants are able to recognize renditions of familiar songs that differ substantially from their own mothers' version. Infants' remarkable generalization abilities raise the question: how variable are the song renditions they hear at home? The current study aims to investigate the pitch and tempo features of parents' repetitions of the same song over the course of a day. We conducted secondary analyses of existing day-long recordings of 28 infants' auditory environments, which are available in the MendozaMusic database. These recordings were collected by an unobtrusive audio recorder worn on the infants' clothing. First, each infants' most frequently heard song was identified. Next, for each instance of that song, the pitch of repeated phrases was analyzed using audio analysis software and double-checked manually by a musically trained researcher. Tempo was measured by the musically trained researcher tapping along to the singing using software that calculated the tapping rate. Preliminary results hint at large individual differences between parents, with some parents displaying high pitch and tempo consistency, and others, extreme variations. This research suggests that previous lab-based research has not captured the full range of parent song that infants hear in their daily lives. It further raises questions about the sources of variability in parent song renditions, and about the impact of that variability on infant auditory development and familiar song recognition.

\section{Communities for change: Understanding and evaluating grassroots projects}

Ilakkiah Chandran, HBSc Candidate [1], Jasjit Sangha, PhD [2], Kosha Bramesfeld, PhD [1]

[1] Department of Psychology, University of Toronto Scarborough, Toronto, Ontario, Canada M1C 1A4

The Communities for Change (C4C) project brought together community leaders who worked on grassroots movements to collectively envision and implement solutions to existing problems within their communities (e.g., affordable housing, food insecurity, etc.). Over 8-weeks, changemakers participated in planning, prototyping and implementation phases while undergoing the Theory $U$ framework. These leaders focused on implementing solutions within their communities while focusing on facilitated learning and innovation. The present study aims to analyze and evaluate components of the $\mathrm{C} 4 \mathrm{C}$ 
UNDERGRADUATE RESEARCH IN NATURAL AND CLINICAL SCIENCE AND TECHNOLOGY (URNCST) JOURNAL Read more URNCST Journal articles and submit your own today at: https://www.urncst.com

projects to understand the conditions that led to and inhibited the success of $\mathrm{C} 4 \mathrm{C}$ projects in different communities. This study utilized transcripts collected during the C4C program evaluation meetings to conduct a secondary analysis. NVivo, a qualitative coding software, was used to code the transcripts under the following headings: Community Building, Prototyping Factors, Success Factors and Transformative Learning. From there, factors that promoted and inhibited the success of C4C projects in different communities were identified and compared to existing literature. The preliminary results of this study indicate that community resilience, mentorship, participant adaptability and relationship-building amongst participants were crucial features that enhanced the success of $\mathrm{C} 4 \mathrm{C}$ projects. Furthermore, the results suggest that the lack of resources and increased discomfort during prototyping inhibited the success of these projects. This project aims to translate the elements and resources required to ensure grassroots projects' success globally for future community-based initiatives in interdisciplinary environments. Furthermore, this study's findings will help develop long-term solutions to mitigate the inequities and challenges faced by global communities. Moreover, this project's results extend to address affordability and accessibility issues when allocating resources to support innovative and holistic grassroots projects. Overall, this project aims to build awareness regarding the tools, resources and factors essential to creating sustainable and collective change globally.

\section{Stories of thriving \& surviving: Using a participatory research design to inform pedagogical tools for disability awareness \\ Laiba Rizwan, HBSc Candidate [1], Kosha Bramesfeld, PhD [1] \\ [1] Department of Psychology, University of Toronto Scarborough, Toronto, Ontario, Canada M1C 1A4}

Within the field of disability studies, using scientific knowledge about disability studies to educate future practitioners is a key focus of knowledge mobilization efforts. Unfortunately, there is a lack of empirically supported training strategies to promote disability awareness, with some tools actually increasing stigma, embarrassment, and social exclusion. Perhaps one reason for the failings of these prior approaches is that they were often developed without the direct input of people with a lived experience of disability. The current project aims to address this limitation by employing a participatory research design, a technique that offers the advantage of empowering and directly involving those with lived experience in the development of a holistic framework for advancing knowledge mobilization strategies around disability awareness. Specifically, five racially diverse disability advocates with experiences living with a disability were surveyed and interviewed to (a) better understand participants' frustrations with existing disability awareness approaches, (b) determine what strategies they have personally used to raise awareness about their own disabilities, and (c) what recommendations they have for improving the representation and contextualization of disability in formalized training tools. Qualitative thematic analysis was conducted to identify and analyze key themes and patterns from the data. Core findings and recommendations to refine future awareness paradigms are made. By allowing participants to share their subjective and objective experiences, I hope to gain a holistic understanding of their experiences. This could complement the design of future disability awareness tools in ways that better represent the social realities of living with a disability.

Boredom and ego-depletion: Analyzing the effects on preference towards physical exercise Melissa J. Agajona, HBSc Candidate [1]

[1] Department of Psychology, University of Toronto, Toronto, Ontario, Canada M1C 1A4

Previous research suggests that self-control, the mechanism that resolves conflict between any two competing goals, is the underlying key to success in varying domains of life. During the replication crisis in psychology, the empirical foundation of the long-celebrated resource model of self-control has come under scrutiny. This model proposes that self-control is akin to the operations of a muscle, in which it has a limited central resource of energy, becoming depleted with use and resulting in a state of ego-depletion. Some preliminary studies have linked ego-depletion to the decrease of blood glucose levels, and as a result, ego-depleted individuals should be averse to exerting more self-control in order to conserve their resources. However, a new model of self-control has surfaced in order to explain any inconsistencies and problems with the resource model of self-control. The process model of self-control proposes that ego-depletion is not about the depletion of an internal resource, but rather a lack of motivation or desire to keep pursuing a task. In particular, this motivational mechanism of ego-depletion is proposed to be mediated by the feelings of fatigue and boredom, both of which encourage an individual to disengage from a current task and bring their attention to seek something more gratifying.

Using a classic between-subjects design, participants undergo a typical sequential task-paradigm with the first task being an effortful cognitive task, in order to induce ego-depletion, and the second task being physical exercise or more of the effortful cognitive task. Their preferences towards physical exercise after engaging in a cognitive effort task are then measured using a

Chandran et al. | URNCST Journal (2021): Volume 5, Issue 4

Page A4 of A6

DOI Link: https://doi.org/10.26685/urncst.266 


\section{UNDERGRADUATE RESEARCH IN NATURAL AND CLINICAL SCIENCE AND TECHNOLOGY (URNCST) JOURNAL}

Read more URNCST Journal articles and submit your own today at: https://www.urncst.com

staircasing procedure. In accordance with the process model of self-control, it is hypothesized that depleted individuals will increase their preference to engage in physical exercise, despite its real caloric costs, because they are bored and tired of the cognitive effortful task.

The challenges faced by LGBTQ+ individuals of Middle Eastern origin: A mixed-methods study Rawan Hedefa, HBSc Candidate [1], Gerald Cupchik, PhD [1] [1] Department of Psychology, University of Toronto Scarborough, Toronto, Ontario, Canada M1C 1A4

The study explored the unique challenges that Middle Eastern LGBTQ+ individuals ( $\mathrm{n}=97$ ) experience. The participants completed three quantitative questionnaires that were developed through factor analysis, which touched on various factors within the different constructs addressed in the study (i.e., the familial, cultural, and self-related challenges this group faces). For the self-questionnaire, sexual orientation concealment, internalized homophobia, and resilience were measured. For the culture questionnaire, appropriateness of same-gender public display of affection, elders \& family's reputation, traditional gender roles, and lack of belongingness in the LGBTQ+ and Middle Eastern community were measured. It was expected that the different familial and cultural challenges would have direct impacts on the level of sexual orientation and internalized homophobia. Indeed, significant positive correlations were found between the aforementioned factors in the quantitative data. With regards to the qualitative aspect of the study, the participants were asked to reflect on their challenges with their sexual minority identity as well as their resilience in overcoming these challenges. These reflections were followed by negative and positive affect scale ratings as well as interpretation scales. The results further revealed significant negative correlations between sexual orientation concealment and positive affect as well as sexual orientation and interpretation. The results also revealed significant positive correlations between resilience and positive affect, sexual orientation and negative affect, internalized homophobia and negative affect, elders \& family's reputation and negative affect, lack of belongingness in the LGBTQ+ and Middle Eastern community and negative affect. The quantitative data alongside the qualitative stories of the participants ultimately highlight the importance of providing customized, culturally adapted, and resilience-based resources for Middle Eastern LGBTQ+ individuals facing challenges with their sexual identity. Thus, further implications for mental health and community-based resources and interventions are discussed in the article.

\section{Conflicts of Interest}

The authors declare that they have no conflict of interests.

\section{Authors' Contributions}

IC: Founded the University of Toronto Scarborough Psychology and Neuroscience Departmental Association Academic Research Panel, served as one of the leads of the planning and organizing committee for the conference, assisted authors with their abstract submissions, drafted the conference abstract booklet and gave final approval of the version to be published.

MK: Served as one of the leads of the planning and organizing committee for the University of Toronto Scarborough Psychology and Neuroscience Departmental Association Academic Research Panel, drafted the conference abstract booklet, gave final approval of the version to be published.

ZS: served as one of the leads of the planning and organizing committee for the University of Toronto Scarborough Psychology and Neuroscience Departmental Association Academic Research Panel, drafted the conference abstract booklet, gave final approval of the version to be published.

\section{Acknowledgements}

We want to acknowledge the entire University of Toronto Scarborough Psychology and Neuroscience Departmental Association (PNDA) Executive Team for being fundamental in the planning and execution of the first annual Academic Research Panel. Also, this conference would have not been possible without the support of the PNDA Faculty Advisor, Dr. Kosha Bramesfeld.

\section{Funding}

This conference was not funded. 
UNDERGRADUATE RESEARCH IN NATURAL AND CLINICAL SCIENCE AND TECHNOLOGY (URNCST) JOURNAL Read more URNCST Journal articles and submit your own today at: https://www.urncst.com

\section{Article Information}

Managing Editor: Jeremy Y. Ng

Article Dates: Received Apr 04 21; Published Apr 2321

\section{Citation}

Please cite this article as follows:

Chandran I, Khan M, Sarwar Z. The University of Toronto Scarborough Psychology and Neuroscience Departmental Association (PNDA) 2021 Academic Research Panel. URNCST Journal. 2021 Apr 23: 5(4).

https://urncst.com/index.php/urncst/article/view/266

DOI Link: https://doi.org/10.26685/urncst.266

\section{Copyright}

(C) Ilakkiah Chandran, Mahnoor Khan, Zanib Sarwar. (2021). Published first in the Undergraduate Research in Natural and Clinical Science and Technology (URNCST) Journal. This is an open access article distributed under the terms of the Creative Commons Attribution License (https://creativecommons.org/licenses/by/4.0/), which permits unrestricted use, distribution, and reproduction in any medium, provided the original work, first published in the Undergraduate Research in Natural and Clinical Science and Technology (URNCST) Journal, is properly cited. The complete bibliographic information, a link to the original publication on http://www.urncst.com, as well as this copyright and license information must be included.

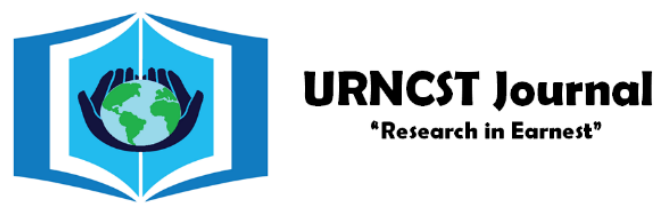

\section{Funded by the Government of Canada}

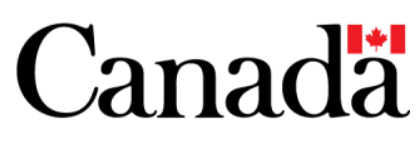

Do you research in earnest? Submit your next undergraduate research article to the URNCST Journal!

| Open Access | Peer-Reviewed | Rapid Turnaround Time | International | | Broad and Multidisciplinary | Indexed | Innovative | Social Media Promoted |

Pre-submission inquiries? Send us an email at info@urncst.com | Facebook, Twitter and LinkedIn: @URNCST

Submit YOUR manuscript today at https://www.urncst.com! 